\title{
Vulture updates - October 2017 - Around the World of Vultures \& VSG activities
}

Multi-species Action Plan (MsAP): On 29 Nov 2016 in Mumbai, India, the co-chairs of the IUCN SSC VSG signed an agreement as co-operating partner with the CMS Raptors MoU. This formalises the VSG's support and commitment to implementation of the Raptors MoU in Africa and Eurasia and further cements the working relationship established as a partner in the drafting of the CMS Vulture MsAP. Members are invited to peruse the formatted version of the Final Draft of the Multi-species Action Plan to Conserve AfricanEurasian Vultures (Vulture MsAP) and also a concise Vulture MsAP summary that are now available online on the CMS COP12 web pages. This Final Draft Vulture MsAP was unanimously endorsed by the CMS Scientific Council at the 2nd Meeting of its Sessional Committee, which was held in July 2017 in Bonn, Germany. Significantly, the meeting also recommended CMS Parties accept the proposals covering all ten species of Old World vulture for listing on Appendix I to the Convention. For more details, please refer to the News item on the Raptors MOU website. A small team of VSG members attended the CMS COP12 in Manila, Philippines from the 2228 Oct 2017 and participated in a Side-Event co-organised with the CMS Raptors MoU Coordinating Unit, BirdLife International and Vulture Conservation Foundation. The event, entitled 'Conserving African-Eurasian vultures for biodiversity and ecosystem services: the role of the Multi-species Action Plan', was held on 24 Oct. Further vulture side events at the meeting featured Indian vultures (hosted by Indian Government), and the uplisting of Lappet-faced Vulture (hosted by the Saudi Wildlife Authority).

The Flyway Action Plan for the Conservation of the Cinereous Vulture (CVFAP) is also being finalised (following wide consultation led by VCF) in time for the CMS meeting - (latest version here). It was developed alongside a revised EU Species Action Plan for the Cinereous Vulture, which EU Member States have already commented upon, and it should appear shortly and is incorporated to 
the MsAP in the same way as the Egyptian Vulture Flyway Action Plan and the SAVE Blueprint for South Asia.

\section{International Vulture Awareness}

Day included 138 events registered worldwide in 32 countries, and we know there were more, with an associated major surge in media publicity. Do take advantage of the excellent downloadable materials (in many languages) on the website, and start planning for next year's event!

\section{African roundup}

The African Wildlife Poisoning Database is now online. This enables registered users to submit information about poisoning incidents and to view basic data on poisoning incidents via a map of Africa. We encourage everyone to submit any recent or historical poisoning incidents and to inform your colleagues/students/ staff about it.

Five species of African vulture have been declared SAFE species by the Association of Zoos and Aquariums (AZA). The SAFE species program is a commitment by AZA to provide special effort and support for protecting designated SAFE species. Corinne Kendall is the program leader.
VulPro is building a new release enclosure, located on the Nooitgedacht Game Reserve, South Africa where a breeding colony of Cape Vultures is located. This is a first of its kind in Africa. The new release /flight enclosure will house captive bred and rehabilitated Cape Vultures from six months up to two years prior to their release.

The Bulgarian Society for the Protection of Birds (BSPB) are coordinating a LIFE project on Egyptian Vultures, titled 'Urgent Action to Strengthen the Balkan Population of the Egyptian Vulture and Secure Its Flyway' as a followup to The Return of the Neophron project. The project aims to reinforce the vulture population in the EU's easternmost range by delivering urgent conservation measures that eliminate major known threats in breeding grounds along the flyway in Mediterranean, Africa and the Middle East. The five year project will involve several partners in 12 countries, four of which are African (Nigeria, Ethiopia, Niger \& Chad). In early Nov 2017, a group of vulture conservationists from southern- \& east Africa will participate in a workshop organized and hosted by the National Socio-Environmental Synthesis Centre (SESYNC) in Annapolis, Maryland, USA. SESYNC integrates science of the 
natural world with science of human behaviour and decision-making, seeking solutions to complex environmental problems. In this instance, scientists will look at current \& possible alternative solutions to the many threats African vultures face. In 2014, Raptors Botswana deployed two satellite transmitters on Hooded Vultures; one bird died within a few months and led the team to a large poisoning incident. The second bird continues to traverse vast areas of northern Botswana and adjacent parts of Namibia, Zambia and Zimbabwe. In March 2017, a further two Hooded Vultures were fitted with transmitters in northern Chobe District. Preliminary data show that they too are ranging widely across international boundaries, and are not restricted to protected areas.

\section{Americas roundup}

North America: The latest official count of world population of California Condors is 446 and growing, with 276 in the wilds of California, Arizona, Utah, and Mexico. There are now 78 condors in the Arizona/Utah population. Four new birds were released in Sept (a further 10 earmarked for release in 2018), and a record number of pairs exhibiting behaviour from which three chicks were confirmed fledged in 2017. The results of Peregrine Fund trapping and lead-testing of $91 \%$ of the birds $(n=69)$ last season unfortunately continued to register beyond sustainable levels of lead exposure as has been the case in previous years. All but two of the 23 showing extreme exposure were treated with chelation therapy and released back into the wild. Two had been severely lead-poisoned and died while undergoing treatment for advanced lead toxicosis. Engagement increases with cooperating agencies, tribes and the public continuing towards the ultimate goal of eliminating this preventable threat. Big-game hunters in parts of Arizona and Utah are responding with requests to either use non-lead ammunition or remove the remains of lead-tainted carcasses from the field. The next step is reaching out to other shooters i.e. small-game, varmint, and furbearer hunters and those who might dispatch moribund stock or wildlife (ranchers and law enforcement). Thanks to grants from the Arizona Game \& Fish Department \& The Phoenix Zoo, 15 new GPS transmitters will be deployed during the upcoming trapping season. Field workers at Hawk Mountain Sanctuary are currently testing the value of behavioral "ground- 
truthing" of 3 satellite tracked American Black Vultures in Pennsylvania, USA. The observational work, which began in early September, physically locates the tracked birds (and that of other wing-tagged individuals) on a weekly basis and then details their behavior via direct observations, to determine what the birds actually are doing. Detailed information regarding roosting, feeding, and social behavior is being recorded via focus animal sampling. If groundtruthing proves successful, behavioral observations will be expanded to include satellite-tracked Turkey Vultures in North, Central, and South America and eventually, will include tracked Hooded Vultures in Africa. Initial observations suggest that this multifaceted approach works, at least for Black Vultures in eastern North America.

Latin America: Incidents of poisoning across the region are apparently increasing. In north Argentina 19 Andean Condors were found dead linked to a camelid carcass that was poisoned. There have been a number of similar separate incidents in 2017, involving GPS-tagged condors found dead. In the same way, Turkey Vultures GPStagged in Patagonia were found poisoned in the same area, and in central Argentina where these birds are passage migrants. Another threat established (in a publication) to be seriously affecting condors and vultures was lead poisoning, and several birds were received for rehabilitation, including fledglings. Black Vulture mortality factors in Patagonia were attributed to poisoning at rubbish dumps and persecution by farmers that consider they are dangerous for livestock. A tagging project is planned for the three vulture species to study their movements and overlap in feeding areas, and to better understand their role in cleaning the environment. Together with field workers at CONICET in Bariloche, Argentina, Hawk Mountain Sanctuary are building a geographically explicit North and South American distribution-and-abundance dataset based on seasonal roadside counts of Turkey and American Black Vultures, from 50 degrees north through 50 degrees south in the New World. This will allow researchers to model the impact of vulture scavenging behavior geographically throughout the Americas, which will be used to build a case for protecting populations of these abundant and widespread species across their range. 


\section{Asia roundup}

In South Asia, plans for the first ever releases of white-rumped vultures in Nepal have progressed, with the first six birds transferred to the pre-release aviaries in April. Six wild birds are now fitted with PTTs, and are so far showing the area to be safe, and regularly crossing into India, where they have highlighted some key feeding sites. If things remain on track then releases are planned for November. Meanwhile in India, the first Haryana releases of captive-bred White-rumped Vultures look set to take place early in 2018 and preparatory work continues including getting the final PTT permissions in place. Safety-testing plans of the Indian Veterinary Research Institute have progressed, but the work has not yet started. This eagerly anticipated step is arguably the most important one as other drugs such as nimesulide which also appear to be toxic to vultures are becoming established in veterinary practice. And the court case is ongoing, where one Indian drug company has challenged the 2015 restriction of the vial size of human diclofenac injections and threatens to reverse this important measure that makes diclofenac less accessible for illegal use by veterinarians. The annual SAVE meeting will take place in Bangladesh in November, and is linked to the InterGovernment Regional Steering Committee meeting in Dhaka. Finally, the Indian Government banned the use of nylon kite strings which have been responsible for many serious bird (and human) injuries, and poses a threat to vultures in some areas.

West Asia: A short film on scavengers at rubbish dumps in Oman is in final editing stages, and Egyptian Vultures still being satellite tracked in Oman, with more planned next year. A publication is in process on this. Eight captive-bred EVs were released in 2017 as part of a reintroduction project at Mt. Carmel, Israel (2015 \& 2016 hatched) bringing the total to 51 captive-bred EVs released since 2004.

Returning EVs include birds hatched from 2011, 2012 and 2013. Overall population of EV in Israel is stable or even slightly growing (55 pairs).

\section{European roundup:}

Poison remains the main threat to vultures in Europe (as it is worldwide) - with notable incidents in Sardinia, and in Spain. However, locally birds are still being shot Griffon Vultures in Armenia, even 
Bearded Vultures in Spain. Electrocution is also a major threat to vultures in Europe - so the news that a Spanish court confirmed legal liability from the utility company involved in a vulture electrocution case was welcome. Lead poisoning kills Bearded Vultures and other vultures too, so some pilot projects testing non-lead ammunition are an important initiative to clarify the extent of this. As part of the LIFE RUPIS project, a number of supplementary feeding sites were established to support Egyptian Vultures, and five adult Egyptian Vultures have been tagged in the Douro canyon, one of the strongholds of the species in Iberia they have all now migrated to Africa. The project also organised a festival in June to celebrate the species. Four captive-bred Egyptian Vultures were released in southern Italy - one of them made it all the way to Africa, while one died and two had to be recaptured.

Bearded Vultures have had a good season in Europe, with two young raised by the reintroduction project in Andalusia (following the first successful breeding two years ago). While in the Alps, 45 pairs produced a record 20 fledglings. In early October, hundreds of people participated in a simultaneous count for International Bearded Vulture
Observation Day (IOD). 18 Bearded Vultures were released in the four reintroduction projects, not without some drama - one of them broke its wing just before release but was eventually rehabilitated and is now flying free in Andalusia, while another dispersed long distance to Germany and had to be re-caught and re-released. Some wild individuals were found weakened and rehabilitated and released, like Lea. Other Bearded Vultures were seen in Poland, Holland, Sweden and Germany. In the French Pyrenees at least 44 pairs bred this year with a much better breeding productivity than of late, whilst a new paper suggested that there is plenty of natural food in the Pyrenees and that the species does not actually need supplementary feeding. In Corsica the species again did not succeed to breed in the wild, but two more captive-bred young were released there, like last year. In midNovember the annual Bearded Vulture meeting will be held in Haute-Savoie, with a very attractive programme.

Eight Cinereous Vultures from Spain were transferred to France for the successful reintroduction project there - this year there were 35 breeding pairs, while the species bred again in the Alentejo region of Portugal, confirming recolonisation 
there. More Cinereous Vultures have been seen in Romania, the Italian eastern Alps, and in northern France, and the species is a rare winter visitor in the Middle East so a bird that entered rehabilitation in Jordan was noteworthy.

Griffon Vultures decreased in Croatia, while record numbers were counted in northern Italy. In Cyprus the very small breeding population bred again after two years without successful breeding. An important colony was affected by the major forest fires that occurred in Portugal this summer, whilst almost 2500 Griffon Vultures were counted summering in the western Alps in 2017 - an increase of $40 \%$ on previous years. A number of Griffon
Vultures have been tagged in Italy and Sardinia and Bulgaria.

A campaign to ban veterinary diclofenac has been relaunched in Europe, to prevent the drug being approved for veterinary use in Portugal - where there is a new request for use, and to try to prevent the renewal of the permit in Spain. Please do sign the petition at www.banvetdiclofenac.com Let us know if you receive this newsletter indirectly and would like to be added to the mailing list, or to be considered for membership of VSG, and please send us any potential contributions for the next newsletter before 30 March 2018.

Chris Bowden

Andre Botha

Co-chairs: Vulture Specialist Group Commission

With thanks to the following contributions:

VSG update Editor \& Asia roundup: Chris Bowden

African Regional Co-chairs: Darcy Ogada, Masumi Gudka

European Regional Co-chair: Jose Tavares

Latin Americas Co-chair: Sergio Lambertucci

North America : Rick Watson, Keith Bildstein, Chris Parish

Additional contributions: Mike McGrady, Ohad Hatzofe, Kerri Wolter, Pete Hancock.

VSG Admin Assistant: Lesley Jerome 